\title{
Analysis of the chemical constitutions of Yaojie shale oil in China by gas chromatography-mass spectrometry (GC-MS)
}

\author{
W. Wang ${ }^{1}$, S. Y. $\mathrm{Li}^{1}$, Y. $\mathrm{Liu}^{2}$, D. K. Qiu ${ }^{2}, \mathrm{Y} . \mathrm{Ma}^{1}$ \& J. X. Wu \\ ${ }^{1}$ State Key Laboratory of Heavy Oil Processing, \\ China University of Petroleum, China \\ ${ }^{2}$ Liaoning Datang International Coal-to-SNG Co. Ltd., China
}

\begin{abstract}
The shale oil from Yaojie oil shale (YSO), Gansu Province, was subjected to acid-base separation to obtain acidic, basic and neutral fractions. The three fractions were characterized by gas chromatography-mass spectrometry (GCMS). The GC-MS analysis showed that the neutral fraction (84.39wt \%) contained C8 C33 normal alkanes, C8 C27 alkenes, benzene, naphthalene, phenanthrene (or paranaphalene) and other constitutions containing more than one benzene rings; the acid fraction (2.44wt\%) mainly contained phenol, naphthol and indenol. Diphenol series were also identified in the acid fraction; the basic component (3.41wt\%) consist of phenylamine, derivatives of pyridine, quinoline series. In this paper, the composition of YSO was widely investigated at the molecular level. The chemical composition of YSO provides important theoretical data for technology development.
\end{abstract}

Keywords: shale oil, oil shale, GC-MS.

\section{Introduction}

Due to the high crude oil prices, the mining and retorting of oil shale has attracted more and more attention to meet the vast demand of energy [1]. Shale oil (SO) is obtained from the pyrolysis process of oil shale, being rich in alkanes, arenes, as well as nitrogen-, sulfur-, and oxygen-containing non-hydrocarbons. Hence, a more in-depth understanding of the molecular composition of SO is vital to technology development, which are valuable chemical raw materials for various applications [2-3]. 
A lot of research has been conducted to analyze the composition of SO. Robert et al. [4] separated the Queensland SO into ten fractions and identified about 500-700 compounds. Guo and Ruan [5] separated two kinds of shale oils boiling < $350^{\circ} \mathrm{C}$ from Fushun and Maoming shale oils, both China, into subgroups by four chromatographic columns in series with deactivated adsorbent. And the fractions were analyzed by gas chromatography-mass spectrometry (GC-MS). The results showed that Fushun SO and Maoming SO contained more than 300 compounds [5]. Two kinds of shale oils from mountainous areas (land) and coastal shelf rocks (sea), both in China, were separated into four fractions using silica gel column chromatography and identified by GC-MS. It is found that there are 269 compounds, with abundant hydrocarbon compounds (79\%), and some sulfur, oxygen and nitrogen compounds in the shale oil from land contains and 284 compounds with a high amount of hydrocarbon and oxygen compounds (60 and $29 \%$, respectively), and some sulfur and nitrogen compounds . in that of sea rocks [6]. Besides, some workers found that the phenols, indanols, naphthols, phenylphenols, fluorenols, phenanthrenols, ketones and esters and other oxycompounds were presented in shale oil and other fuel oils [7-10].

In this paper, a comprehensive compositional analysis of YSO was performed using GC-MS. This effort lays the groundwork for a better understanding of the heteroatom-containing species present in shale oil.

\section{Experimental}

\subsection{Material and separation methods for GC-MS analysis}

Shale oil was obtained from Yaojie oil shale (Gansu province, China) by pyrolysis at $550^{\circ} \mathrm{C}$. The separation steps and result of YSO are shown in Figure 1 and Table 1 , respectively.

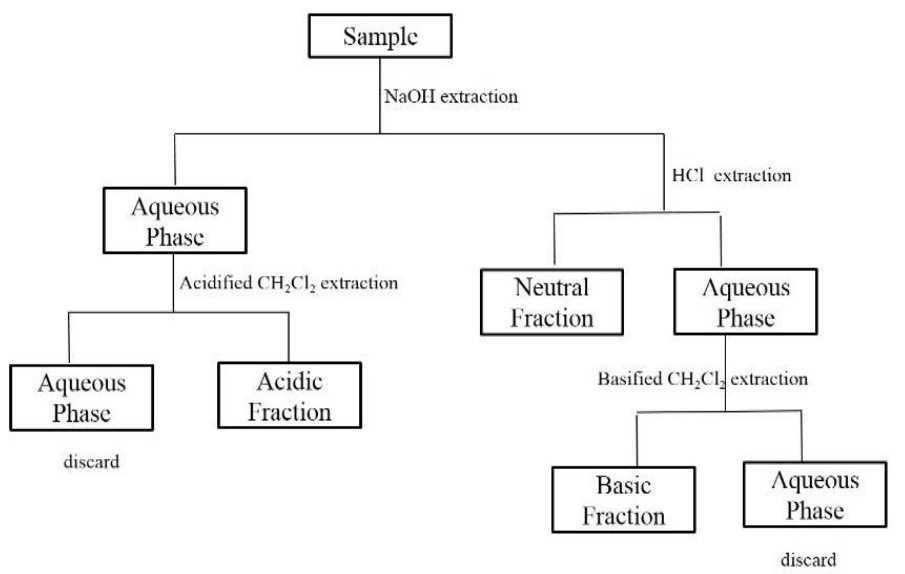

Figure 1: The separation scheme of acrid-, basic- and natural-fractions of shale oil. 
Table 1: Results of separation of samples according to acidic-, neutral- and basic-fractions.

\begin{tabular}{|l|c|c|c|}
\hline & Acid fraction & Neutral fraction & Basic fraction \\
\hline Percentage, wt\% & 2.44 & 83.39 & 3.41 \\
\hline
\end{tabular}

\subsection{GC-MS analysis}

A Thermo-Finnigan Trace DSQ GC-MS coupled with an HP-5MS (30m $\times$ $0.25 \mathrm{~mm} \times 0.25 \mu \mathrm{m})$ fused silica capillary column was used to analyze the composition of shale oil. The mass spectrometer was operated with an electron impact (EI) source at a $70 \mathrm{eV}$ ionization energy. The mass range was set to 30-550Da at 1.2s scanning intervals. The oven temperature was maintained at $50^{\circ} \mathrm{C}$, increased to $120^{\circ} \mathrm{C}$ at $20^{\circ} \mathrm{C} / \mathrm{min}$, then increased to $250^{\circ} \mathrm{C}$ at $4^{\circ} \mathrm{C} / \mathrm{min}$, after that increased to $310^{\circ} \mathrm{C}$ at $3^{\circ} \mathrm{C} / \mathrm{min}$. At last it held constant at $310^{\circ} \mathrm{C}$ for $30 \mathrm{~min}$. The sample was injected at $300^{\circ} \mathrm{C}$. The amount of the injected sample was $1 \mu \mathrm{L}$. Helium was used as a carrier gas at a flow rate of $1 \mathrm{~mL} / \mathrm{min}$.

\section{Results and discussion}

All the fractions were subjected to GC-MS analysis. Figure 2 shows the total ion of three fractions of YSO. It is obvious that both are complex mixtures, with a wide range of components present.

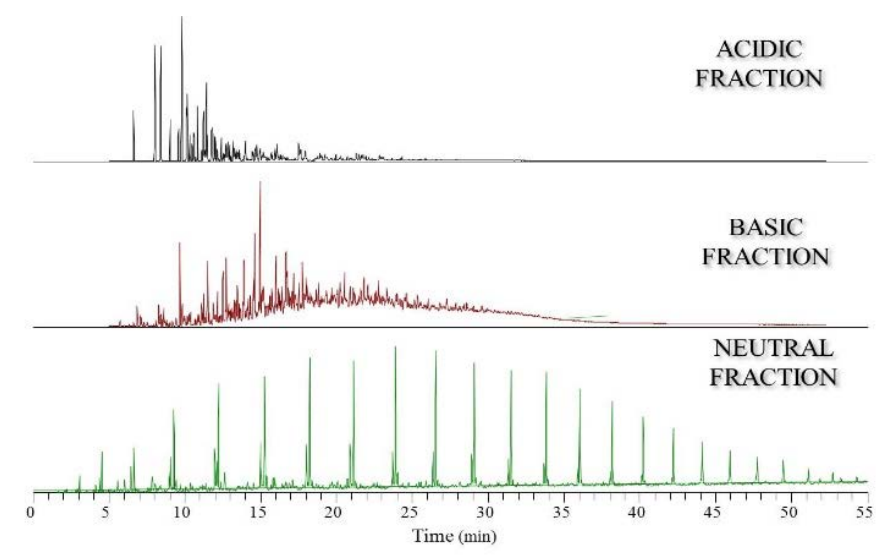

Figure 2: Total ion chromatogram of different fractions of YSO.

\subsection{Analysis of neutral fraction (NF)}

As seen from Figure 3, mass chromatograms m/z 85 and 97 showed the distribution of n-alkanes and n-alkenes, respectively. Normal alkanes with 8-33 carbons and Normal alkenes with 8-27 carbons were abundant in NF. Besides, 
benzene and alkyl-benzenes (C1-C4), naphthalene series (C0-C4), anthracene or phenanthrene in series (C0-C3), which are commonly found in petroleum and coal extracts, were also abundant in NF in Figures 3-6. Above all, about 130 compounds were represented in NF of YSO.

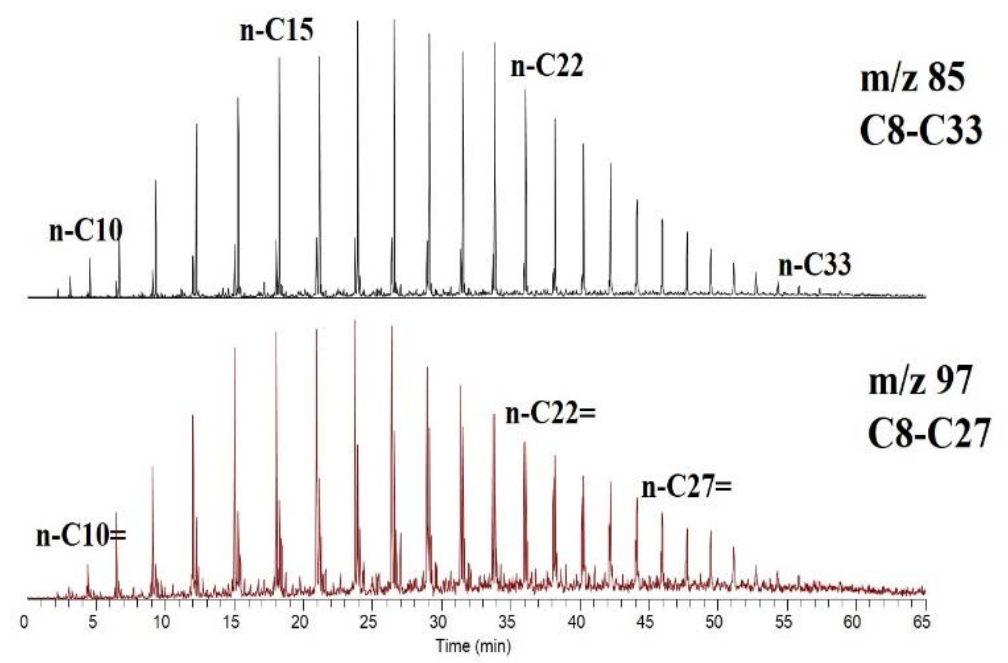

Figure 3: Gas chromatogram of n-alkanes and n-alkenes in NF of YSO.

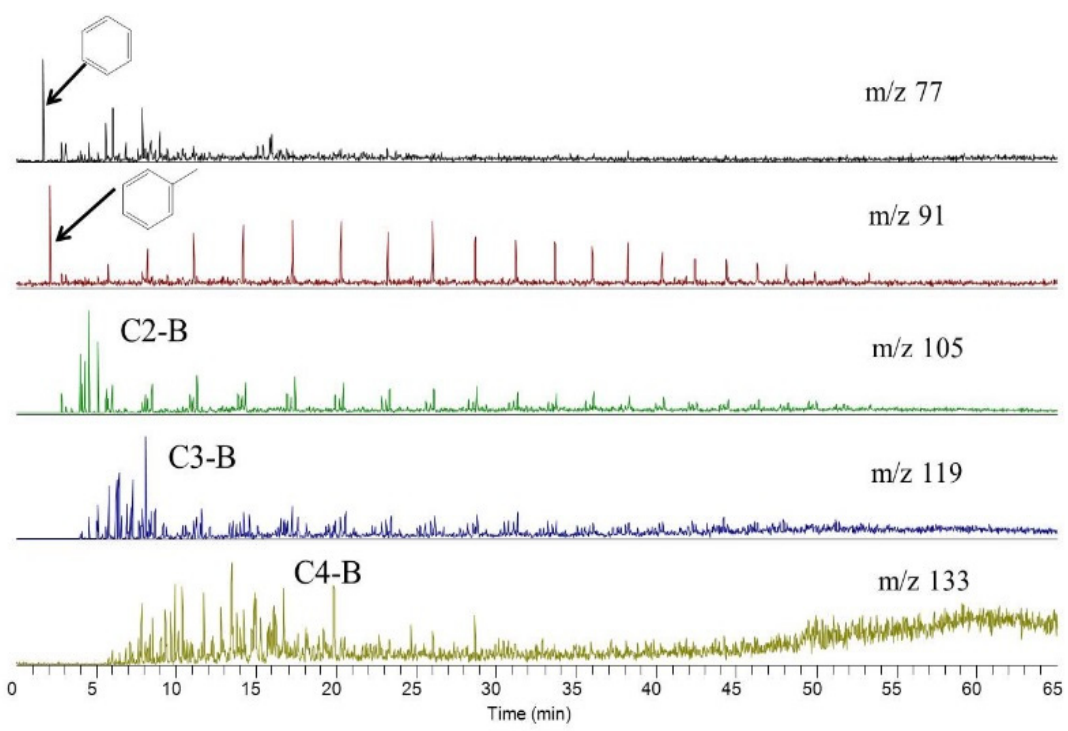

Figure 4: Gas chromatogram of benzene and alkyl-benzenes in NF of YSO. 
$\mathrm{m} / \mathrm{z} 128$

C1-naphthalene

$\mathrm{m} / \mathrm{z} 142$

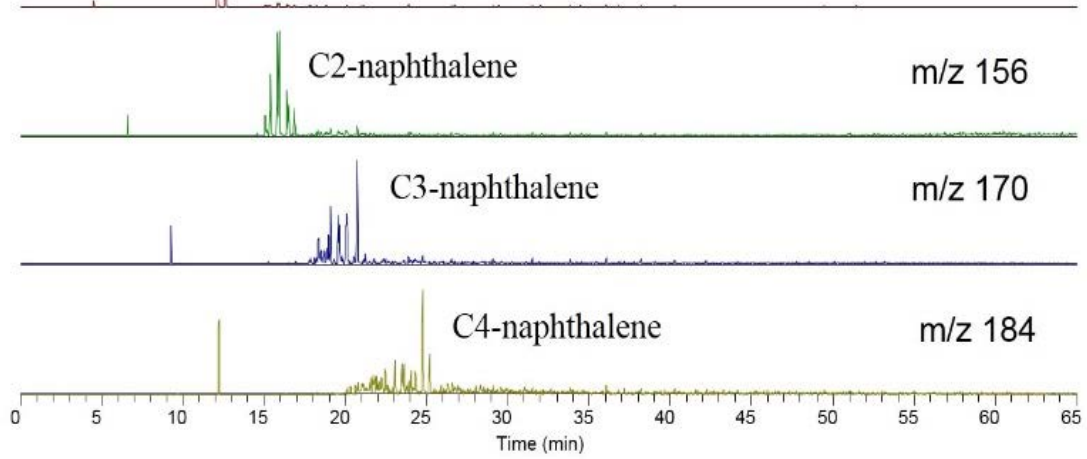

Figure 5: Gas chromatogram of naphthalene series in NF of YSO.

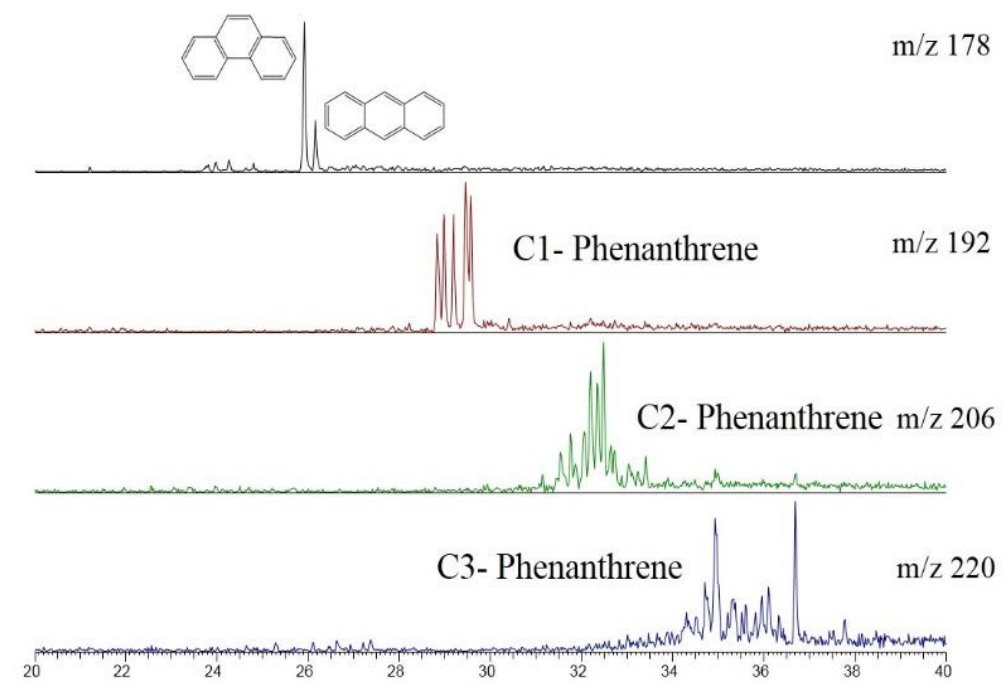

Figure 6: Gas chromatogram of anthracene or phenanthrene in series in NF of YSO.

\subsection{Analysis of acidic fraction (AF)}

Based on the results of GC-MS analysis, Figures 7-10 show the distribution of phenol series (C0-C4), naphthol series (C0-C4), indanols series (C0-C3) and 
diphenol series (C0-C3), respectively. When the carbon number of alkyl is above 2 (including 2), there are many isomer compounds. And we have found almost 120 compounds in AF.

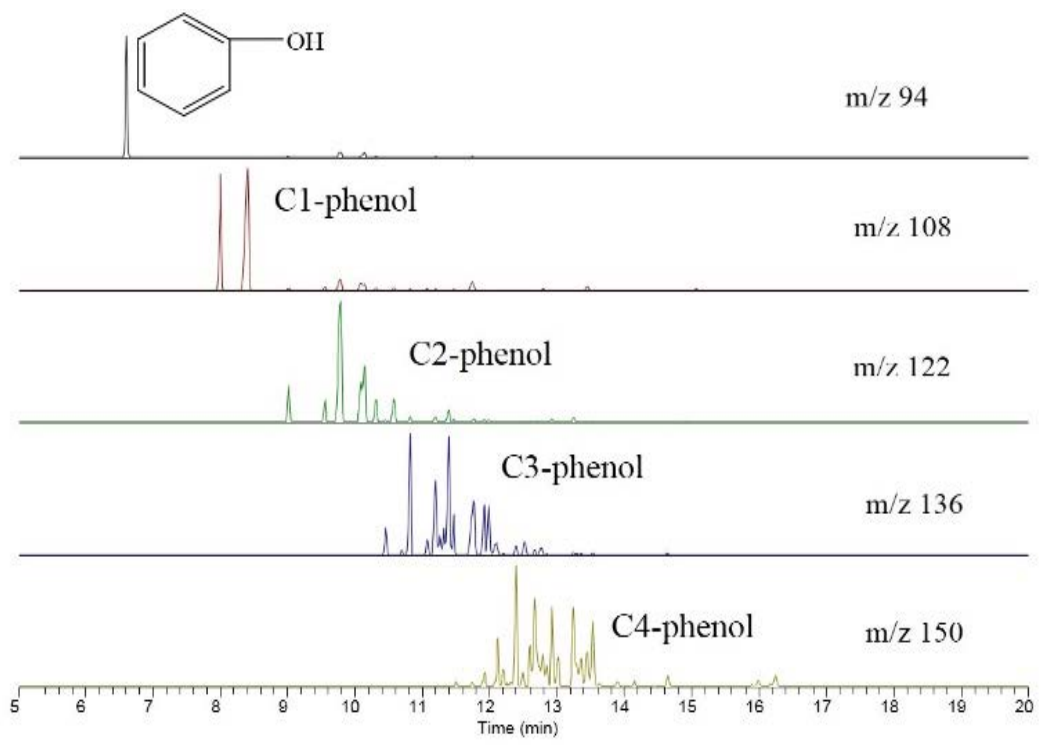

Figure 7: Gas chromatogram of phenol series in AF of YSO.

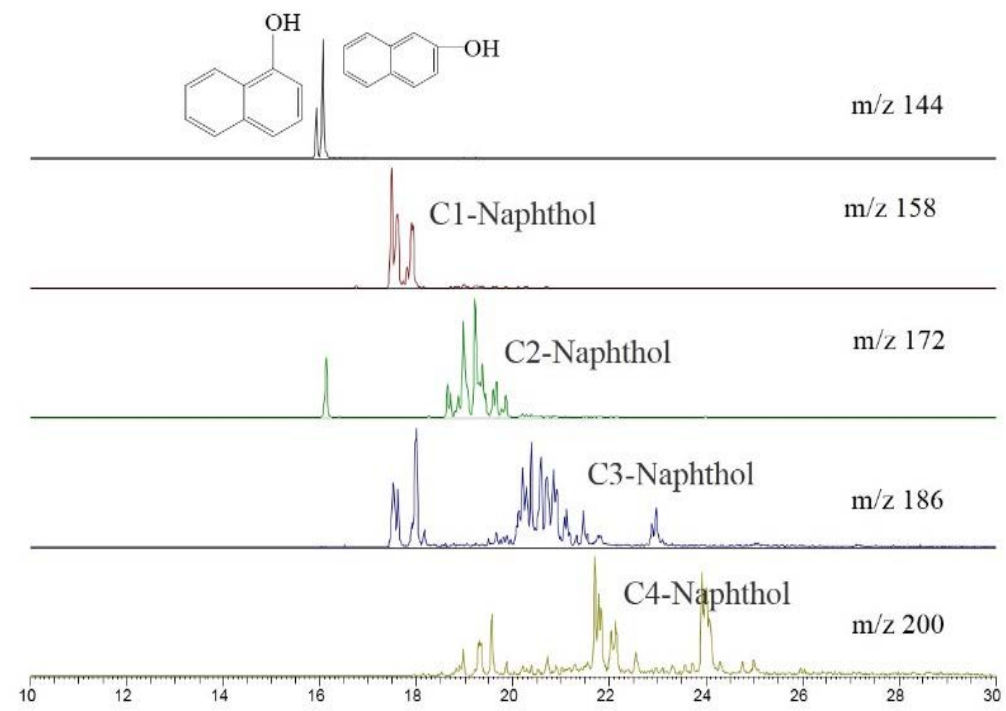

Figure 8: Gas chromatogram of naphthol series in AF of YSO. 


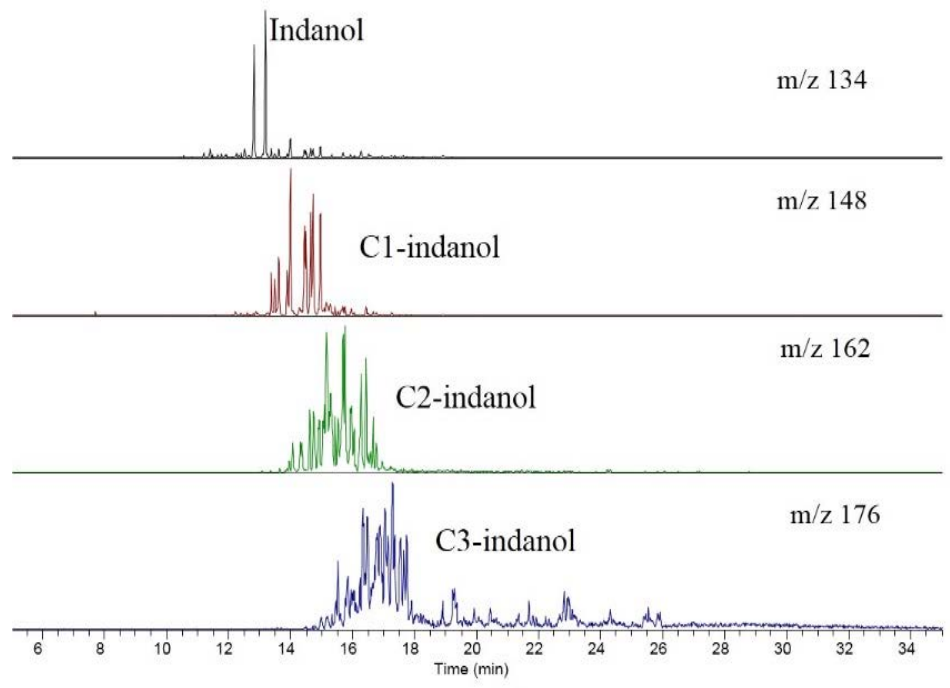

Figure 9: Gas chromatogram of indanols in AF of YSO.

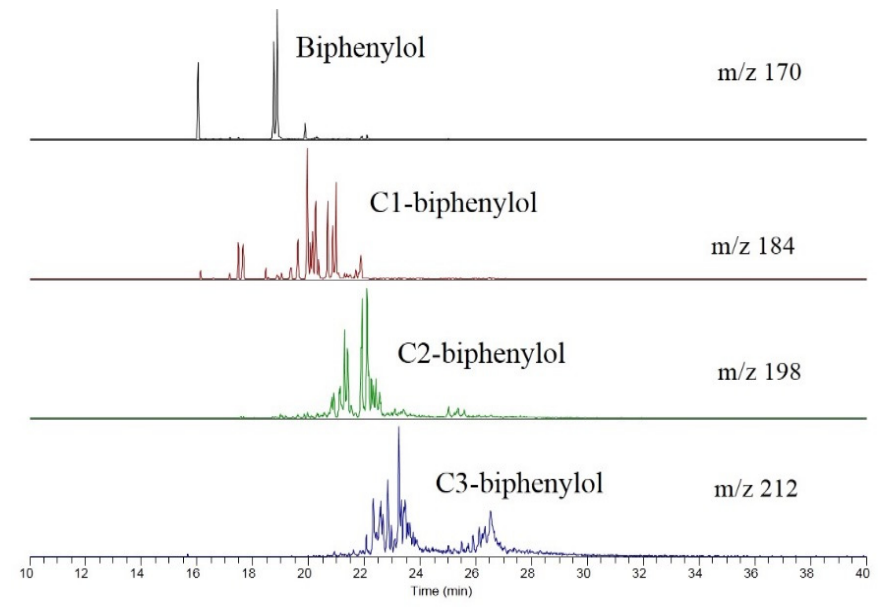

Figure 10: Gas chromatogram of biphenol series in AF of YSO.

\subsection{Analysis of basic fraction (BF)}

The quinoline series (C0-C3), acridine series (C0-C2) and phenylamine series (C0-C3) were identified by extracting the characteristic mass fragment m/z 129 of alkyl quinoline, 179 of alkyl acridine and 93 of alkyl phenylamine, respectively. And the results were shown in Figures 11-13. Obviously, it had separated the isomer compounds for each specific compounds. And about 80 compound were identified in BF of YSO. 
The acidic (2.44\%), basic (3.41\%), and neutral (83.39\%) fractions were obtained from the shale oil from Yaojie oil shale (YSO), according to acid base separation. And about 130 compounds including C8-C33 alkane, C8-C27 alkene, benzene and alkyl-benzenes (C1-C4), naphthalene series (C0-C4), anthracene or phenanthrene in series (C0-C3), were found in NF. Almost 120 compounds, phenol series (C0-C4), naphthol series (C0-C4), indanols series (C0-C3) and diphenol series (C0-C3) were identified in AF. About 80 compound including quinoline series (C0-C3), acridine series (C0-C2) and phenlyamine series (C0-C3) were identified in BF of YSO.

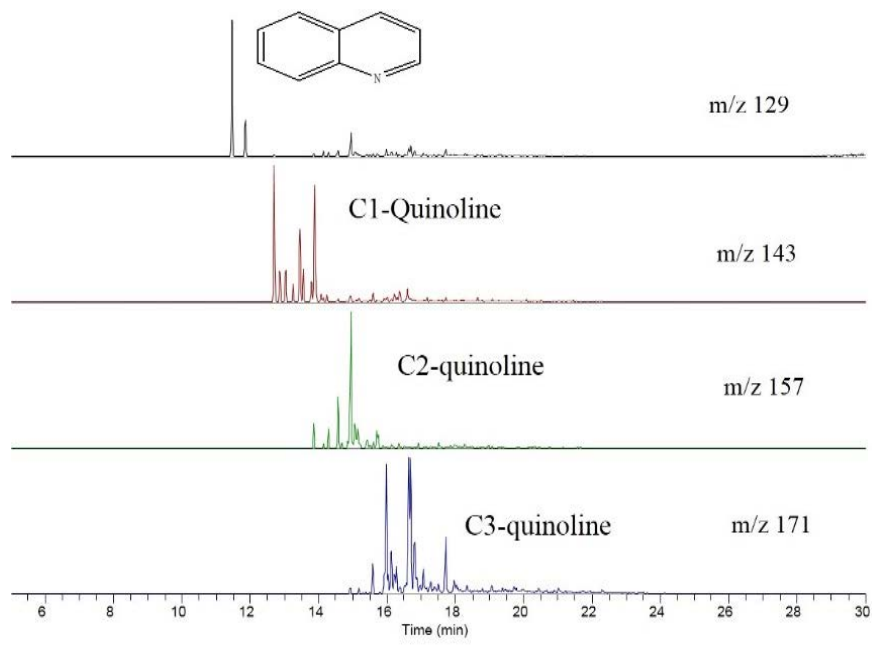

Figure 11: Gas chromatogram of quinoline series in BF of YSO.

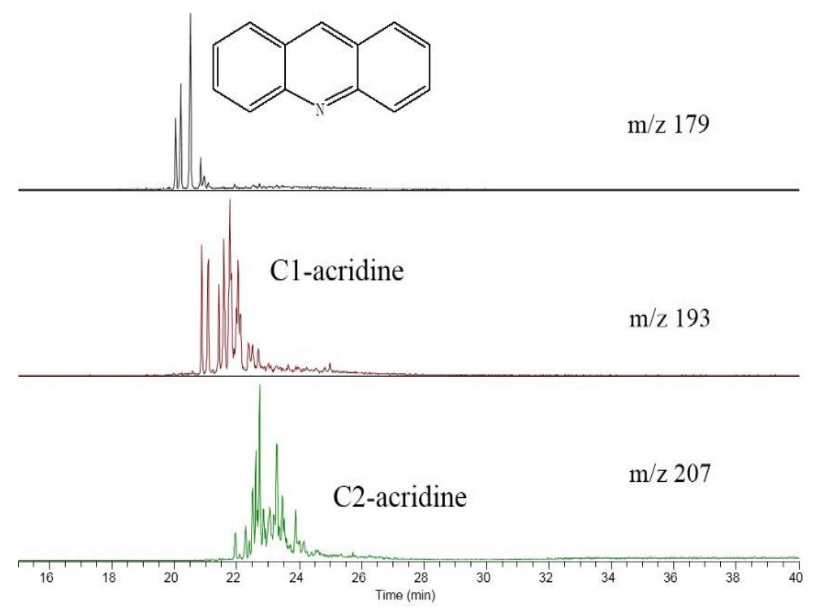

Figure 12: Gas chromatogram of acridine series in BF of YSO. 


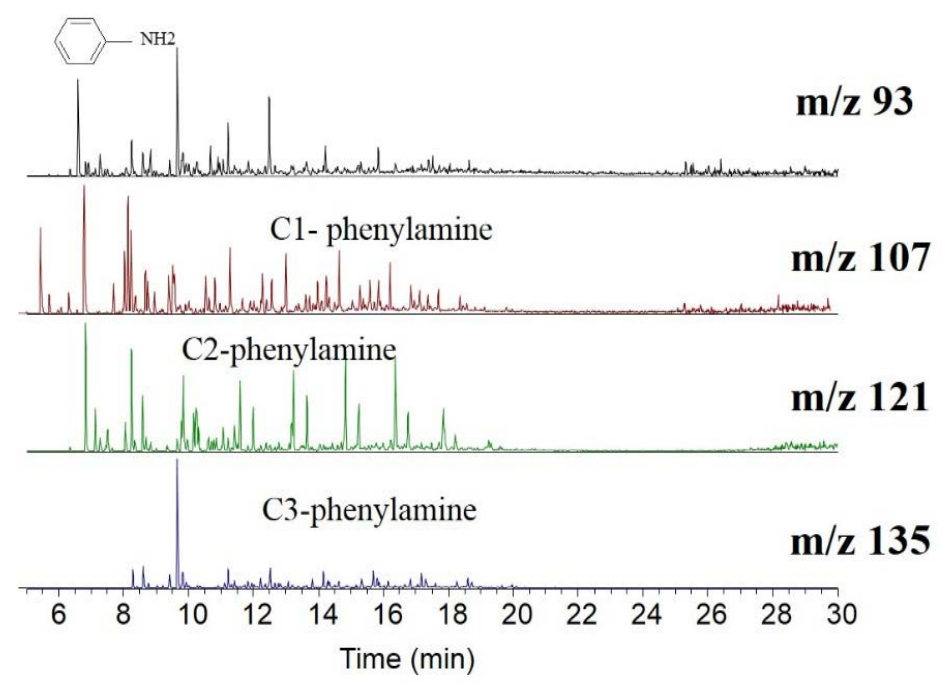

Figure 13: Gas chromatogram of phenlyamine series in BF of YSO.

\section{Conclusions}

A compositional analysis of chemical compounds presented in Yaojie shale oil (YSO) was performed using GC-MS. The following conclusions were drawn:

(1) The main fraction of YSO was neutral fraction with $83.39 \%$, which was chiefly consisted of $\mathrm{C} 8 \sim \mathrm{C} 33$ hydrocarbons.The relative concentration of each n-paraffin gradually decreased with molecular carbon atoms increasing. And it can be used produce the gas oil and diesel through hydrofining and other processing technologies.

(2) It was found that the acid fraction of YSO were phenols, indanols, naphthols, phenylphenols and their derivatives. But the acidic fraction was low, so the processing of shale oil to produce synthetic fibers, engineering plastics and other products is unavailable.

(3) The basic fraction is mainly the basic nitrogen compounds,including pyridines ,quinolines and phenylamine. Most of nitrogen compounds are toxic, resulting in the unsteadiness of properties of shale oil. Inhence they had to be reduced or removed in the hydrofining and other processing technologies of shale oil.

\section{Acknowledgements}

The authors are grateful for the National Basic Research Program of China (973 programs, no. 2014CB744302) and the Taishan Scholar Constructive Engineering Foundation of Shandong province, China (no. ts20120518). 


\section{References}

[1] Qian, J. L., Yin, L. Oil Shale - Petroleum Alternative. China Petrochemical Press, Beijing, 2010.

[2] Qian, J. L., Wang, J. Q., Li, S. Y. Oil shale development in China. Oil Shale, 20(3S), pp. 356-359, 2003.

[3] Williams P.T, Ahmad N. Investigation of oil-shale pyrolysis processing conditions using thermo gravimetric analysis. Applied Energy, 66, pp. 113-133 2000.

[4] Robert A. Regtop, Phillip T. Crisp, John Ellis, Chemical characterization of shale oil from Rundle, Queensland. Fuel, 61(2), pp. 185-192, 1982.

[5] Guo, S. H., Ruan, Z. The composition of Fushun and Maoming shale oils. Fuel, 74(11), pp. 1719-1721, 1995.

[6] Zhu, Z. R. Analysis of composition of shale oils from different places. Acta Petrolei Sinica (Petroleum Processing Section), 9(3), pp. 66-71, 1993 (in Chinese).

[7] Geng CC, Li SY, Ma Y, et al. Analysis and identification of oxygen compounds in Longkou shale oil and Shenmu coal tar. Oil Shale, 29, pp. 322-333, 2012.

[8] Amer MW, Mitrevski B, Roy Jackson W, Chaffee AL, Marriott PJ. Multidimensional and comprehensive two-dimensional gas chromatography of dichloromethane soluble products from a high sulfur Jordanian oil shale. Talanta, 120, pp. 55-63, 2014.

[9] Willsch H, Clegg H, Horsfield B, Radke M, Wilkes H. Liquid chromatographic separation of sediment, rock, and coal extracts and crude oil into compound classes. Anal Chem, 69, pp. 4203-4209, 1997.

[10] Wang, M., Guo, S. H., Ruan, Z., Zhang, L. F. Analysis of oxygen-containing compounds in light fraction of shale oils. I. Separation of oxygencontaining compounds in shale oils. Acta Petrolei Sinica (Petroleum Processing Section), 9(3), pp. 10-15, 1993 (in Chinese). 